\title{
Orientation and spatial-frequency-specific surround effects on binocular rivalry
}

\author{
BARRY MAPPERSON \\ University of Tasmania, Hobart, Tasmania, Australia \\ and \\ WILLIAM LOVEGROVE \\ University of Wollongong, Wollongong, New South Wales, Australia
}

\begin{abstract}
The presence of an annular grating surrounding rivaling gratings was found to significantly reduce the dominance of a component that was similar in both spatial frequency and orientation. This effect, which transfers interocularly, would seem to implicate cortical or higher mechanisms in binocular rivalry suppression.
\end{abstract}

Adaptation to a single grating is known to reduce the proportion of time for which gratings of similar orientation and spatial frequency will be perceived as dominant in binocular rivalry (Blake \& Overton, 1979; Blake, Westendorf, \& Overton, 1980; Kakizaki, 1950a, 1950b). Since effects similar to the aftereffects of grating inspection can typically be produced when the inspection stimulus is presented simultaneously with the test stimulus, in the form of annular surrounds (e.g., Lovegrove, 1977; Mapperson \& Lovegrove, 1978; Tolhurst \& Thompson, 1975), it might be expected that an analogous surround effect upon relative dominance in binocular rivalry could be demonstrated. The following experiments test this hypothesis.

\section{METHOD}

\section{Experiment 1}

Subjects. Eight volunteers, who were screened for normal stereopsis with Julesz patterns, participated as subjects.

Apparatus. Photographic reproductions of a sine-wave grating with a Michelson contrast of $\mathbf{0 . 6}$ were presented in a Scientific Prototype tachistoscope. Each eye received a composite stimulus consisting of a $1.5^{\circ}$ grating centered within an annulus (inner diameter $=1.5^{\circ}$, outer diameter $=5^{\circ}$ ). The annular surround contained either a blank field or a grating at various orientations. The space-average luminance of each component of both composite stimuli was $3 \mathrm{~cd} / \mathrm{m}^{2}$; the spatial frequency of all gratings was 4 cycles/degree.

Procedure. Ss were randomly allocated to either a monocular (M) or an interocular (I) group. For both groups, the annulus presented to the left eye was blank in all trials. The annulus presented to the right eye contained either a blank field or a grating oriented vertically or $5^{\circ}$, $10^{\circ}, 20^{\circ}$, or $45^{\circ}$ counterclockwise from vertical. The presentation order of these six conditions was randomized for each observer.

For the $M$ group, the center portion of the stimulus presented to the right eye was a vertical grating and the center portion of the stimulus presented to the left eye was a horizontal grating. For the I group, these pairings were reversed, as is illustrated in Figure 1.

Correspondence may be sent to William Lovegrove, Department of Psychology, University of Wollongong, Wollongong, New South Wales 2500, Australia.
Consequently, a vertical grating in the surround was the same orientation as the central grating being presented to the same eye for the $\mathbf{M}$ group, but it was the same orientation as the central grating presented to the other eye for the I group. Preliminary testing showed that under these circumstances the central portions of the stimuli rivaled vigorously, while a grating present in one surround tended to dominate more or less continuously over the blank surround presented to the other eye.

\section{Experiment 2}

The method of Experiment 2 was identical to that of Experiment 1, with two exceptions: (1) all gratings presented in the surround were oriented vertically and (2) a range of differing spatial frequencies was presented $(1,2,4,8$, and 16 cycles/degree).

\section{RESULTS AND DISCUSSION}

The mean number of seconds per minute for which observers recorded the horizontal $(\mathrm{H})$ and the vertical (V) center gratings as dominant under each condition was calculated; the $\mathrm{H}-\mathrm{V}$ difference was taken as the measure of relative dominance. The changes in dominance relative to the control condition (blank surrounds to both eyes), with varying surround orientation and varying surround spatial frequency, are shown in Figures $2 a$ and $2 b$, respectively.

Analyses of variance and subsequent individual comparisons using Duncan's new multiple range test were carried out on these data. In Experiment 1, orientation of the surround had a significant effect $[F(5,30)=14.8$, $p<.001]$, with surrounds oriented vertically or $5^{\circ}, 10^{\circ}$, or $20^{\circ}$ from vertical inducing significantly greater horizontal dominance than the surrounds oriented $45^{\circ}$ from vertical or the control condition. Furthermore, the $20^{\circ}$ grating produced significantly less effect than did the vertical, $5^{\circ}$, or $10^{\circ}$ gratings, indicating that the effect is restricted to a limited range of relative orientations.

Experiment 2 demonstrated that the spatial frequency of the surround grating was also a significant variable $[F(5,30)=11.5, p<.001]$. Vertical surround gratings of 2,4 , and 8 cycles/degree induced significantly greater horizontal dominance than did the 1 or 16 cycles/degree 
(a)
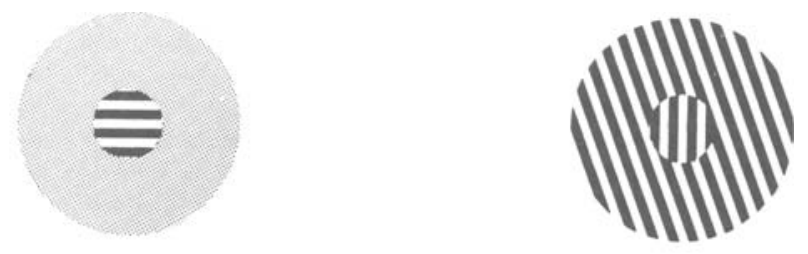

(b)

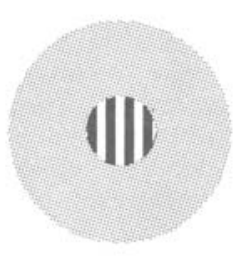

right eye

left eye

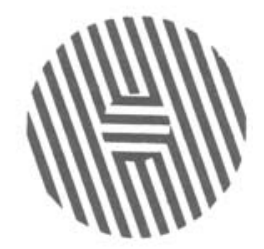

Figure 1. A typical display presented to each eye for (a) the $M$ and (b) the $I$ conditions.

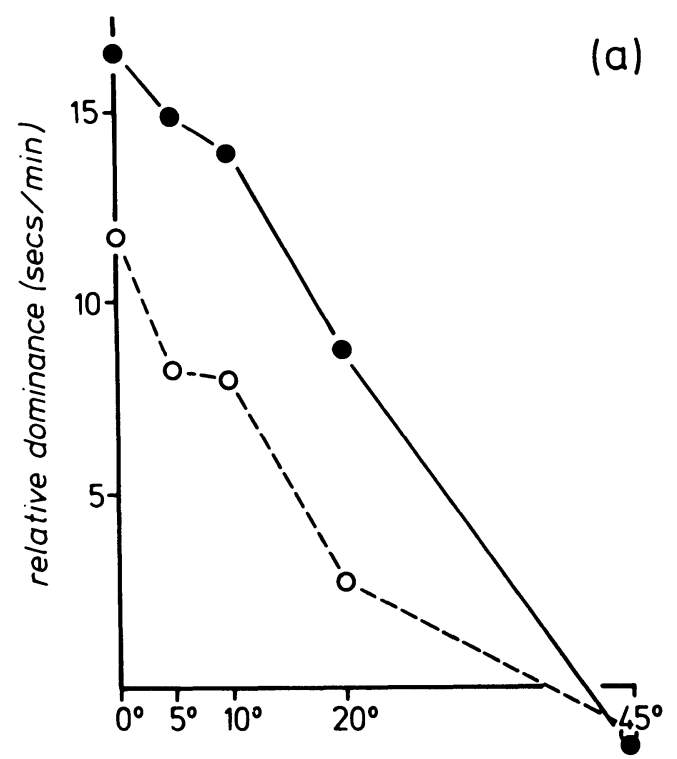

orientation of surround grating (degrees from vertical)

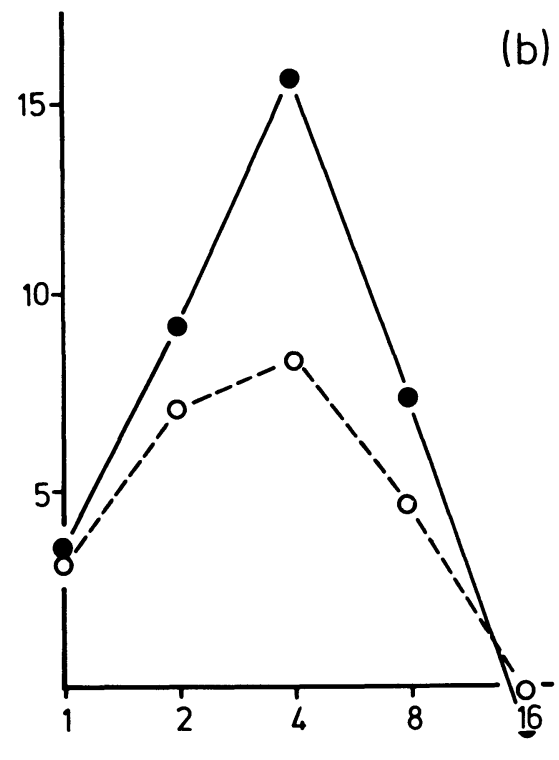

spatial frequency of surround grating ( cycles/deg)

Figure 2. Change in dominance $(\mathrm{H}-\mathrm{V})$ relative to control condition as a function of (a) orientation and (b) spatial frequency of surround gratings $(\bullet-\bullet=$ monocular condition, $\circ---\circ=$ interocular condition). 
surrounds or the control condition. The 8 cycle/degree surround, however, produced significantly less effect than did the 4 cycle/degree surround gratings.

Differences between the $\mathbf{M}$ and I groups did not attain significance, and there were no significant interaction effects.

The orientation and spatial frequency specificity of this effect, together with the interocular transfer, are comparable to other studies using successive presentation and implicate cortical or higher level mechanisms in this surround effect.

\section{REFERENCES}

Blake, R., \& Overton, R. (1979). The site of binocular rivalry suppression. Perception, 8, 143-152.
Blake, R., Westendorf, D. H., \& Overton, R. (1980). What is suppressed during binocular rivalry? Perception, 9, 223-231.

KAKIZAKI, S. (1950a). The effects of preceding conditions upon binocular rivalry (I). Japanese Journal of Psychology, 20, 24-32.

KAKIZAKI, S. (1950b). The effects of preceding conditions upon binocular rivalry (II). Japanese Journal of Psychology, 20, 11-17.

LOVEGROVE, W. (1977). Inhibition between channels selective to contour orientation and wavelength in the human visual system. Perception \& Psychophysics, 22, 49-53.

Mapperson, B., \& Lovegrove, W. (1978). Spatial frequency and orientation specificity of simultaneous and successive inhibition on monocular rivalry. Vision Research, 18, 1461-1463.

TolmURST, D. J., \& ThомPSON, P. G. (1975). Orientation illusions and aftereffects: Inhibition between channels. Vision Research, 15, 967-972.

(Manuscript received June 17, 1990.) 